\title{
Efficacy of Amla (Emblica officinanis) and Shibe yamani (potash alum) in the management of Candida vaginitis: a randomized standard controlled trial
}

\section{Masuma Zaki, Wajeeha Begum, Mariyam Roqaiya*}

\begin{abstract}
Department of Ilmul Qabalat Wa Amraze Niswan, National Institute of Unani Medicine, Kottigepalya, Bengaluru-91, Karnataka, India
\end{abstract}

Received: 15 March 2016

Accepted: 12 April 2016

\section{*Correspondence:}

Dr. Mariyam Roqaiya,

E-mail: dr.mroqaiya@gmail.com

Copyright: (C) the author(s), publisher and licensee Medip Academy. This is an open-access article distributed under the terms of the Creative Commons Attribution Non-Commercial License, which permits unrestricted non-commercial use, distribution, and reproduction in any medium, provided the original work is properly cited.

\begin{abstract}
Background: It has been estimated that $75 \%$ of all females experience at least one episode of Candida vaginitis with approximately $40-50 \%$ reporting a recurrence during their lifetime. The symptoms of vulvovaginal candidiasis are often painful and uncomfortable to the patient. The objective of this study was to assess the efficacy of Amla and Shibe yamani in the management of Candida vaginitis.

Methods: This randomized, single blind, standard controlled study was done to compare the efficacy of Amla and Shibe yamani against fluconazole and $2 \%$ miconazole on diagnosed subjects of Candida vaginitis. Test group ( $\mathrm{n}=30)$ received Amla with honey orally and Shibe yamani intra-vaginally at bed time for 3 wks. Whereas control group received standard regime of single dose fluconazole $150 \mathrm{mg}$ orally and $5 \mathrm{~g}$ of miconazole $2 \%$ cream intravaginally for 7 days. The primary outcome measure was relief in the vulvovaginal pruritus (reduction in 5D itch score). Secondary outcome measures included change in wet mount and improvement in vaginal discharge.

Results: Vulvovaginal pruritus significantly decreased $(\mathrm{P}<0.001)$ after intervention in the two groups. Marked improvement was observed in vaginal discharge $(\mathrm{P}<0.001)$ in both the groups.70\% of patients in test group and $80 \%$ in control group showed change in wet mount.

Conclusions: Test drugs provide statistically significant improvement in vulvovaginal pruritus, vaginal discharge and in wet mount test without any apparent side effects. It can serve as an alternative treatment for Candida vaginitis.
\end{abstract}

Keywords: Candida vaginitis, Amla; Shibe yamani, Fluconazole, Vulvovaginal pruritus

\section{INTRODUCTION}

Candida vaginitis is a common cause of infective vaginal discharge experienced by women. ${ }^{1}$ Each year an estimated 10 million health care office visits to gynaecologists are due to vulvovaginitis. ${ }^{2}$ Among the many causes of vaginitis, Candida vaginitis is the second most common cause after bacterial vaginosis and is diagnosed in up to $40 \%$ of women with vaginal complaints. ${ }^{3}$ It is a disease caused by abnormal growth of yeast-like fungi in the mucosa of female genital tract, classified by WHO as a sexually transmitted disease of frequent sexual transmission. ${ }^{4}$ Several behavioural factorssuch as frequent sexual intercourse, oral sex, use of high oestrogen oral contraceptives, condoms, spermicides etc. and host-related risk factors such as antibiotics use, uncontrolled diabetes, conditions with high reproductive hormone levels, genetic predisposition etc. have been associated with VVC and recurrent episodes. ${ }^{3}$ Although vaginal candidiasis is treatable, when left untreated is a possible risk for acquisition of HIV/AIDS as well as other complications such as PID, infertility, ectopic pregnancy, pelvic abscess, menstrual disorders, spontaneous abortion and premature delivery. ${ }^{5}$ Studies have found that women with recurrent vaginal yeast infections are more likely to experiment with alternative therapies due to relatively lower cost. An estimated $42 \%$ of patients with RVVC have resorted to alternative therapies. ${ }^{2}$ Candida infections are usually treated with an array of antimycotic agents such as 
azoles, polyenes, echinocandins, allylamines and other derivatives but the emergence of antimycotic resistant candidal pathogens, especially the potential widespread dissemination of resistance has become a major public health concern. The prevalence of VVC is therefore expected to increase. Antifungal resistance has been reported in most Candida species, which are the aetiological agents of VVC in addition to other adverse effects of the drugs. Thus there is a need for alternative or adjunct bio-antimycotic means of controlling pathogenic Candida species that infect humans. Studies are also being conducted on the prospects for development of vaccine to prevent and control vaginal candidiasis, which would benefit a large number of women who suffer from this debilitating syndrome. ${ }^{6}$ Amla has got habis, qabiz, mubarrid, mussaffie khoon properties and Shibe yamani is having qabiz, habis, mujaffif, musakkin and mane' sailan effect. ${ }^{7-13}$ Pharmacological studies has also confirmed that Amla contains antifungal, antibacterial, antiviral, anti-inflammatory, analgesic, cooling, antidiabetic, antioxidant, immunomodulator, astringent and resistance building properties. ${ }^{14-16}$ Whereas Shibe yamani is having antifungal, antibacterial, antiinflammatory and astringent properties. ${ }^{17-20}$ Keeping in view the properties of Amla and Shibe yamani this study was carried out to scientifically evaluate their efficacy in the management of Candida vaginitis.

\section{METHODS}

This randomized single blind standard controlled study was conducted in the Dept. of Ilmul Qabalat Wa Amraze Niswan, National Institute of Unani Medicine Hospital, Bangalore, from Feb 2013 to Feb 2014. Keeping in consideration the availability of patients and limited resources 45 patients were recruited for the present study. Patients were allocated randomly to either of the test $(n=30)$ or control group $(n=15)$. Randomisation was done by lottery method/random number table. Prior to initiation of the study, the protocol and informed consent were reviewed and approved by institutional ethical committee, NIUM, Bangalore, with IEC No: NIUM/IEC/2011-12/12/ANQ/04. Data were collected by history, clinical examination and Laboratory investigations.

\section{Inclusion criteria}

Married patients in the age group of 18- 45 years complaining of vulvovaginal pruritus, vaginal discharge, dysuria and dyspareunia.

\section{Exclusion criteria}

Systemic illness, blood stained discharge, sexually transmitted infections, malignancy, pregnant and lactating women and the patients who had received antifungals or antibiotics within previous two weeks.

Patients fulfilling inclusion criteria were enrolled in the study after obtaining informed consent. In each patient a detailed history was evaluated with basic information. Duration of presence of presenting complaint and associated symptoms were enquired. Participants underwent a complete general physical examination including height, weight, BMI and measurements of vitals. Systemic examination of CNS, CVS, RS, abdominal examination and gynaecological examination (P/S, P/V and breast examination) was done in each patient. Per speculum and per vaginal examinations were done by placing the patient in lithotomy position after emptying the bladder. Under a good source of light local examination of external genitalia to look for signs of erythema, oedema and excoriation was made. A sterile speculum without lubricant was placed; vagina and cervix were examined for abnormal inflammation and secretions in terms of colour, consistency and odour. Cases revealing cheesy or white, thick and curdy discharge adherent to vaginal wall were suggestive of Candida vaginitis. Sample of vaginal discharge was taken from the upper wall of the vagina and placed on clean dry slide. A drop of $10 \% \mathrm{KOH}$ solution was added and covered with a clean cover slip. Then the slide was examined microscopically to notice the presence of budding yeast or pseudohyphae. After speculum examination bimanual vaginal examination was done for assessment of uterine size, position, mobility and condition of adnexa. Any mass, tenderness in the fornices and pouch of Douglas was noted. Following thorough evaluation of history and clinical examination, patients were subjected to baseline investigations CBP, ESR, CUE, HIV, VDRL, LFT, RFT, thyroid profile, RBS, Pap smear, USG pelvis.

Test group $(\mathrm{n}=30)$ received Amla (Emblica officinalis) with honey orally and Shibe yamani (potash alum) intravaginally at bed time for 3 wks. Dried fruit of Amla was grinded to make fine powder (sufoof). In each $4 \mathrm{gms}$ of sufoof e Amla $7 \mathrm{ml}$ of pure honey was mixed for one dose. Accordingly in 28gms of sufoof e Amla, $50 \mathrm{ml}$ of honey was mixed for one week dose and was dispensed in air tight pet jar weekly. Honey was used as corrective (musleh) of Amla. Shibe yamani biryan $4 \mathrm{gms}$ had to be mixed with $30 \mathrm{ml}$ of distilled water for one dose. Shibe yamani biryan was dispensed in lock bag and distilled water in $250 \mathrm{ml}$ bottle for one week dose. Patients were advised to take preparation in a dosage of $4 \mathrm{gms}$ orally twice a day. Tampons dipped in lotion of Shibe yamani biryan $(4 \mathrm{gms} / 30 \mathrm{ml})$ had to be used intra-vaginally at bed time daily. In control group one tablet of fluconazole $150 \mathrm{mg}$ was given in a lock bag and miconazole $2 \%$ cream was given in $50 \mathrm{gm}$ pet jar. Fluconazole $150 \mathrm{mg}$ tablet had to be taken orally whereas $5 \mathrm{gms}$ of miconazole $2 \%$ cream had to be applied intra-vaginally daily at bed time for 7 consecutive days. Treatment was subsequently started in patients fulfilling the inclusion criteria. The test drug was given for 3 weeks and standard drug was given for 7 days. After which an assessment of white discharge and pruritus were made. Biochemical estimations were repeated after the completion of trial.

Effectiveness of trial drugs were assessed by subjective and objective parameters. Subjective parameters included 
the severity of pruritus vulva assessed at baseline, for three consecutive weeks during treatment and fortnightly for two visits after treatment. For assessment of pruritus vulva $5-D$ itch scale was used. It is a brief, single page questionnaire for the multidimensional quantification of pruritus that is sensitive to change over time. 5-D scores can potentially range between 5 (no pruritus) and 25 (most severe pruritus). Objective parameters included quantity and character of white discharge assessed by per speculum examination and presence or absence of fungal spores and hyphae assessed by $\mathrm{KOH}$ wet mount. Objective parameters were assessed before and after treatment.
Student t test (two tailed, independent) has been used to find the significance of study parameters on continuous scale between two groups (inter group analysis) and paired proportion test has been used for within groups (intra group) analysis on metric parameters. Student t test (two tailed, dependent) has been used to find the significance of study parameters on continuous scale within each group. Chi-square/ Fisher Exact test has been used to find the significance of study parameters on categorical scale between two or more groups.

\section{RESULTS}

Table 1: Baseline demography of the patients with Candida vaginitis in test and control group.

\begin{tabular}{|c|c|c|c|c|}
\hline Characteristics & Test group $(\mathbf{n}=\mathbf{3 0})$ & Control group (n=15) & Total $\quad(n=45)$ & P value \\
\hline \multicolumn{5}{|l|}{ Age (years) } \\
\hline $21-25$ & $8(26.7 \%)$ & $1(6.7 \%)$ & $9(20 \%)$ & \\
\hline $26-30$ & $10(33.3 \%)$ & $6(40 \%)$ & $16(35.6 \%)$ & \\
\hline $31-35$ & $5(16.7 \%)$ & $5(33.3 \%)$ & $10(22.2 \%)$ & $\mathrm{P}=0.500$ \\
\hline $36-40$ & $6(20 \%)$ & $3(20 \%)$ & $9(20 \%)$ & \\
\hline$>40$ & $1(3.3 \%)$ & $0(0 \%)$ & $1(2.2 \%)$ & \\
\hline Mean \pm SD & $30.13 \pm 6.22$ & $31.40 \pm 5.15$ & $30.56 \pm 5.86$ & \\
\hline \multicolumn{5}{|l|}{ Occupation } \\
\hline House wife & $23(76.7 \%)$ & $14(93.3 \%)$ & $37(82.2 \%)$ & \\
\hline House maid & $1(3.3 \%)$ & $0(0 \%)$ & $11(2.2 \%)$ & \\
\hline Factory worker & $1(3.3 \%)$ & $0(0 \%)$ & $1(2.2 \%)$ & $\mathrm{P}=0.897$ \\
\hline Tailor & $4(13.3 \%)$ & $1(6.7 \%)$ & $5(11.1 \%)$ & \\
\hline Teacher & $1(3.3 \%)$ & $0(0 \%)$ & $1(2.2 \%)$ & \\
\hline \multicolumn{5}{|l|}{ Education } \\
\hline Illiterate & $2(6.7 \%)$ & $2(13.3 \%)$ & $4(8.9 \%)$ & \\
\hline Primary & $14(46.7 \%)$ & $7(46.7 \%)$ & $21(46.7 \%)$ & \\
\hline Secondary & $10(33.3 \%)$ & $4(26.7 \%)$ & $14(31.1 \%)$ & $\mathrm{P}=0.941$ \\
\hline Higher secondary & $3(10 \%)$ & $1(6.7 \%)$ & $4(8.9 \%)$ & \\
\hline Graduate & $1(3.3 \%)$ & $1(6.7 \%)$ & $2(4.4 \%)$ & \\
\hline \multicolumn{5}{|l|}{ Diet } \\
\hline Mixed/non-veg & $28(93.3 \%)$ & $14(93.3 \%)$ & $42(93.3 \%)$ & $\mathrm{P}=1.000$ \\
\hline Veg & $2(6.7 \%)$ & $1(6.7 \%)$ & $3(6.7 \%)$ & \\
\hline \multicolumn{5}{|l|}{ Nutritional status } \\
\hline Poor & $4(13.3 \%)$ & $2(13.3 \%)$ & $6(13.3 \%)$ & \\
\hline Average & $18(60 \%)$ & $8(53.3 \%)$ & $26(57.8 \%)$ & $\mathrm{P}=0.903$ \\
\hline Good & $8(26.7 \%)$ & $5(33.3 \%)$ & $13(28.9 \%)$ & \\
\hline \multicolumn{5}{|l|}{ BMI $\left(\mathrm{kg} / \mathrm{m}^{2}\right)$} \\
\hline$<25$ & $17(56.7 \%)$ & $9(60 \%)$ & $26(57.8 \%)$ & \\
\hline $25-30$ & $12(40 \%)$ & $4(26.7 \%)$ & $16(35.6 \%)$ & $\mathrm{P}=0.681$ \\
\hline$>30$ & $1(3.3 \%)$ & $2(13.3 \%)$ & $3(6.7 \%)$ & \\
\hline Total Mean \pm SD & $24.55 \pm 3.44$ & $24.05 \pm 4.49$ & $24.39 \pm 3.78$ & \\
\hline \multicolumn{5}{|l|}{ SES } \\
\hline Lower & $1(3.3 \%)$ & $1(6.7 \%)$ & $2(4.4 \%)$ & \\
\hline Upper lower & $13(43.3 \%)$ & $8(53.3 \%)$ & $21(46.7 \%)$ & $\mathrm{P}=0.849$ \\
\hline Lower middle & $11(36.7 \%)$ & $4(26.7 \%)$ & $15(33.3 \%)$ & \\
\hline Upper middle & $5(16.7 \%)$ & $2(13.3 \%)$ & $7(15.6 \%)$ & \\
\hline
\end{tabular}


Table 2: Comparative evaluation of vulvovaginal pruritus (5D itch score).

\begin{tabular}{|llll|}
\hline VVP & Test group & Control group & P value \\
\hline $\begin{array}{l}\text { Before } \\
\text { treatment }\end{array}$ & $19.10 \pm 3.21$ & $18.40 \pm 2.79$ & 0.476 \\
\hline $\begin{array}{l}\text { After } \\
\text { treatment }\end{array}$ & $6.67 \pm 3.57$ & $5.93 \pm 1.67$ & 0.455 \\
\hline Difference & 12.43 & 12.47 & - \\
\hline P value & $<0.001 * *$ & $<0.001 * *$ & - \\
\hline
\end{tabular}

Table 3: Comparative evaluations of $\mathrm{KOH}$ wet mount.

\begin{tabular}{|c|c|c|c|c|}
\hline $\begin{array}{l}\mathrm{KOH} \\
\text { wet } \\
\text { mount }\end{array}$ & BT & AT & $\begin{array}{l}\% \\
\text { change }\end{array}$ & $P$ value \\
\hline \multicolumn{4}{|c|}{ Test group } & \multirow{3}{*}{$<0.001 * *$} \\
\hline Positive & $30(100 \%)$ & $9(30 \%)$ & -70.0 & \\
\hline Negative & $0(0 \%)$ & $21(70 \%)$ & +70.0 & \\
\hline \multicolumn{4}{|c|}{ Control group } & \multirow{4}{*}{$<0.001 * *$} \\
\hline Positive & $15(100 \%)$ & $3(20 \%)$ & -80.0 & \\
\hline Negative & $0(0 \%)$ & $12(80 \%)$ & +80.0 & \\
\hline $\mathrm{P}$ value & 1.000 & 0.475 & - & \\
\hline
\end{tabular}

Table 4: Comparative evaluation of white discharge per speculum.

\begin{tabular}{|c|c|c|c|c|}
\hline WDPV & BT & AT & $\begin{array}{l}\% \\
\text { change }\end{array}$ & P value \\
\hline \multicolumn{4}{|l|}{ Test group } & \multirow{5}{*}{$<0.001 * *$} \\
\hline Nil & $0(0 \%)$ & $21(70 \%)$ & +70.0 & \\
\hline Mild & $7(23.3 \%)$ & $9(30 \%)$ & +6.7 & \\
\hline Moderate & $23(76.7 \%)$ & $0(0 \%)$ & -76.7 & \\
\hline Profuse & $0(0 \%)$ & $0(0 \%)$ & 0.0 & \\
\hline \multicolumn{4}{|l|}{ Control } & \multirow{6}{*}{$<0.003^{* *}$} \\
\hline Nil & $0(0 \%)$ & $8(53.3 \%)$ & +53.3 & \\
\hline Mild & $6(40 \%)$ & $7(46.7 \%)$ & +6.7 & \\
\hline Moderate & $9(60 \%)$ & $0(0 \%)$ & -60.0 & \\
\hline Profuse & $0(0 \%)$ & $0(0 \%)$ & 0.0 & \\
\hline $\mathrm{P}$ value & 0.245 & 0.271 & - & \\
\hline
\end{tabular}

There were no significant difference between the groups concerning baseline characteristics with $\mathrm{P}>0.05$ (Table 1). The mean range of VVP (5D itch score) in test group before treatment was $19.10 \pm 3.21$ and it reduced to $6.67 \pm 3.57$ after treatment with a difference of 12.43 . In control group it was $18.40 \pm 2.79$ before treatment and reduced to $5.93 \pm 1.67$ after treatment with a difference of 12.47. The intra group difference of $5 \mathrm{D}$ itch score is highly significant in both the study groups with $\mathrm{P}<0.001$ (Table 2). As shown in table. 3 before intervention all the study subjects $(100 \%)$ in both the groups presented with fungal buds or hyphae on $\mathrm{KOH}$ wet mount test. After completion of treatment no fungal buds or hyphae were detected in $70 \%$ of test group and $80 \%$ of control group participants. Here intra group analysis gives a highly significant $(\mathrm{P}<0.001)$ value whereas no significant difference was observed in inter group analysis. It is approximately similar in both the groups showing equivalent efficacy of test drug to control drug. On speculum examination all participants presented with white discharge which was significantly improved after treatment (Table 4). In test group improvement was $70 \%$ and control group exhibited $53.3 \%$ improvement in WDPV. Intra group analysis before and after treatment was highly significant $(\mathrm{P}<0.001)$ in both the groups and inter group analysis exhibited no significant difference $(\mathrm{P}>0.05)$ after treatment i.e. effect of both the intervention were comparable.

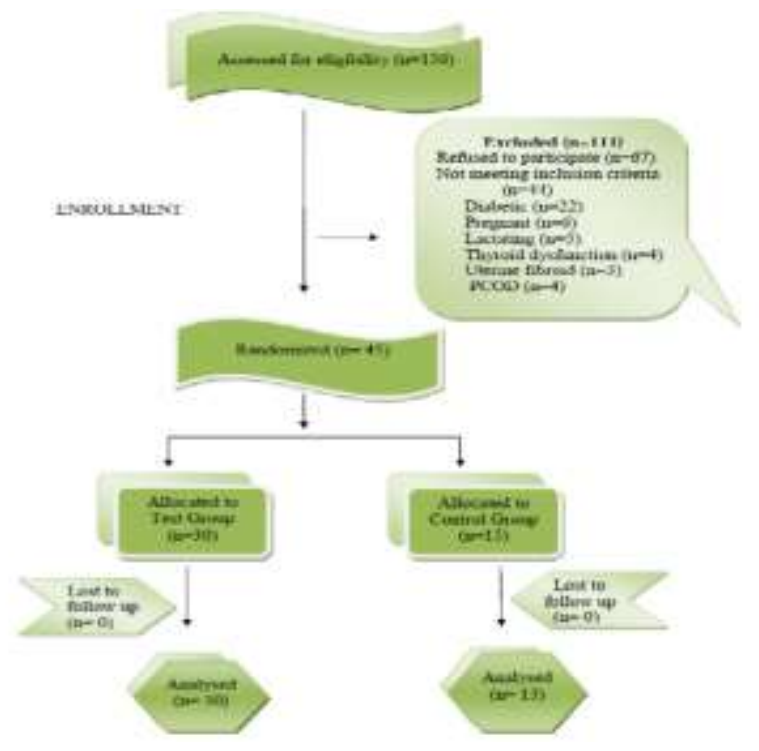

Figure 1: Flow diagram of participants.

\section{DISCUSSION}

Candida vaginitis presents with common symptoms like itching, vaginal discharge and burning sensation that affects the quality of life of many women. Generally the affected women will turn to self-medication with over the counter antifungal drugs. It is prudent that the side effects of oral antifungals have to be born in mind in treating a relatively harmless non-life threatening condition. Patients who opt for oral antifungal agents for personal preference should be adequately informed of its potential side effects, if long term usage is required. On the other hand Unani system of medicine is bestowed with a cache of herbal and mineral origin medicinal wealth. A number of drugs have been mentioned in Unani authentic literature to treat vaginal discharge and vulvovaginal pruritus which are the salient features of Candida vaginitis.

There was no significant difference between the groups concerning baseline characteristics with $\mathrm{P}>0.05$ (Table 1). Mean age of the patients included in study was $30.13 \pm 6.22$ in test group and $31.40 \pm 5.15$ in control group ranging from 21-45 years. Maximum number of participants (55\%) belongs to age group of 21-30 years. Aring et al also reported highest incidence of $\mathrm{VVC}$ in age group 21-30 years (64.9\%) followed by 31-40 years $(17.45 \%)$ and lower incidence in age above 40yrs (7\%). 
$82 \%$ of patients included in this study were housewives. Similar findings were observed by Reza et al. in which $81 \%$ of women were housewives and rest were working women. ${ }^{21}$ In present study majority of participants (84\%) belong to low socioeconomic class (upper lower, lower middle, lower). This is in accordance to the Unani concept. Eminent Unani physicians has highlighted the association of low socioeconomic status with occurrence of sailanur rehm. ${ }^{22}$ Sarain et al. also found an association of low socioeconomic status with prevalence of Candida species in $87 \%$ of participants of their study. ${ }^{23}$

Unani physicians described the cause of disease as zofe in quwae rehm and accumulation of rutoobat. ${ }^{13}$ The excellent response of test drugs was due to the qabiz. ${ }^{7-9,12}$ effect of Amla which helped in absorption of excessive rutoobat. It strengthens the quwae rehm also by its muqawwi action. ${ }^{9,12}$ Along with the local effect produced by Shibe yamani which absorbs excessive discharge due to its mujaffif and qabiz action. ${ }^{10,11,13}$ Thus there was no culture media for yeast to grow and proliferate. In the absence of discharge (irritant) and active organism, as well as due to the musakkin (soothing) effect of alum there was a relief in vulvovaginal pruritus. ${ }^{12}$ This improvement in the vaginal discharge may be attributed to the higher content of tannins, flavonoids, alkaloids, phenolic compounds, antioxidants and considerable amount of micronutrients such as chromium, zinc and copper present in the Emblica officinalis. ${ }^{15}$

Improvement in the $\mathrm{KOH}$ wet mount may be due to antifungal properties of Amla and Shibe yamani proved by earlier research. ${ }^{17,23}$ Regarding the nature and quantity of discharge in all the study participants the colour of discharge was white. $64.4 \%$ of patients had moderate discharge, $28.9 \%$ had scanty discharge and only $6.7 \%$ had profuse discharge. Curdy discharge was present in $88.9 \%$ of patients and rest had $(11.1 \%)$ mucoid discharge. In $97.8 \%$ of patients, discharge was non-offensive whereas in $2.2 \%$ malodorous discharge was present. This is in accordance with Unani concept that specifies odourless and colourless discharge as an indication of ghalbae balgham. ${ }^{25}$ In present study majority of patients had balghami mizaj. Hence from this statement it can be inferred that Candia vaginitis is a type of sailanur rehm which occurs due to alteration in the quality and quantity of balgham. In other words Candida vaginitis is a disease condition described centuries back in classical Unani text as sailane balghami. Normalcy of abnormal balgham was restored by dafe balgham and musaffie akhlat property of Amla. ${ }^{9}$

It can be inferred from the above findings that Amla and Shibe yamani was found as an effective alternative treatment in the treatment of Candida vaginitis with no obvious adverse effects rather it is equivalent in efficacy to standard drugs i.e. fluconazole and miconazole. Being natural agent and free of side effects, it can be considered superior to standard control. It can provide an alternative substitute for costly antifungal drugs, especially in the country like India where majority of population belong to lower socioeconomic group.

\section{CONCLUSION}

Amla and Shibe yamani are equivalent in efficacy to fluconazole and miconazole in the management of Candida vaginitis. A remarkable relief in vulvovaginal pruritus and white discharge was found after treatment. Relief in symptoms was due to the habis, qabiz, mujaffif, mane' sailan, musakkin, mubarrid, and musaffie khoon properties as well as effects of tannins, flavonoids and antioxidants present in test drugs. The promising results of the study have certain limitations due to a non elevated number of patients and a short follow-up period. There is need to perform similar study in large number and for a longer duration.

Candida vaginitis is prevalent in diabetics. Hence it is recommended to conduct clinical trial of Amla without honey (used as musleh of Amla) by using other muslehat for islah of Amla as mentioned in Unani literature. So that result can be generalised to all the patients of Candida vaginitis.

In conclusion, the results of this clinical study/trial indicate that Amla and Shibe yamani possess properties that warrant further clinical studies in a larger number of patients with vulvovaginal yeast infection to confirm its efficacy and tolerability.

\section{ACKNOWLEDGEMENTS}

Authors are thankful to the Director, National Institute of Unani Medicine, Bengaluru for providing all facilities to carry out the research work.

\section{Funding: Not required}

Conflict of interest: None declared

Ethical approval: The study was approved by the Institutional Ethics Committee

\section{REFERENCES}

1. Heng LZ, Chen Y, Tan TC. Treatment of recurrent vulvo-vaginal candidiasis with sustained-release butoconazole pessary. Singapore med J. 2012;53(12):e269-71.

2. Lauren B, Lambert LC, Soper DE. Vaginitis: making sense of over-the-counter treatment options. Infectious disease in obstetrics and gynaecology. 2007;1-4.

3. Achkar JM, Fries BC. Candida infections of the genitourinary tract. Clinical microbiology reviews. 2010;23(2):253-73.

4. Dota KFD, Consolaro MEL, Svidzinski TIE, Bruschi ML. Antifungal activity of Brazilian propolis microparticles against yeasts isolated from vulvovaginal candidiasis. Evidenced-based complementary and alternative medicine. 2011;1-8. 
5. Nwadioha SI, Egah DZ, Alao OO, Iheanacho E. Risk factors for vaginal candidiasis among women attending primary health care centres of Jos, Nigeria. Journal of clinical medicine and research. 2010;2(7):110-3.

6. Ogunshe AAO, Omotoso MA, Bello VB. The in vitro antimicrobial activities of metabolites from Lactobacillus strains on Candida species implicated in Candida vaginitis. Malaysian $\mathrm{J}$ Med Sci. 2011;18(4):13-25.

7. Hakeem MA. Bustanul Mufradat. New Delhi: Idarae Kitabul Shifa; 2002. pp. 90-91, 176-177.

8. Baitar I. AlJami al Mufradat al Advia wa Alaghzia (Urdu Translation). Vol I. New Delhi: CCRUM; 2000. pp. 129-131.

9. Najmul Ghani. Khazianul Advia. Lucknow: Munshi Naval Kishore Press; YNM. pp. 187-189,482-485.

10. Ayub M. Tarjumah Aqsarai sharah mojaz (urdu translation ). vol I. Lucknow: Munshi Naval Kishore Press; YNM. pp. 693-694.

11. Ibrahim al Maghrabi AS. Kitab al- Fatah fi al tadawi (Urdu translation). 1st ed. New Delhi: Govt. of India Ministry of Health \& Family Welfare Dept. of Ayush; 2007. pp. 107,212-213.

12. Kabeeruddin. Makhzanul Mufradat. New Delhi: Idara Kitabul Shifa; 2007. pp. 49- 50,141-142.

13. Sina I. Al Qanoon Fit Tib (Urdu trans. by Kantoori GH). New Delhi: Idarae Kitabul Shifa; YNM. pp. 454, 1065, 1095.

14. Nath A, Raghunatha P, Joshi SR. Diversity and Biological Activities of Endophytic Fungi of Emblica officinalis, an Ethnomedicinal Plant of India. The Korean Society of Mycology. 2012;40(1):8-13.

15. Arora A, Kumar I, Sen R, Singh J. Emblica officinalis (Amla): Physico-Chemical and Fatty Acid Analysis from Arid Zone of Rajasthan. International journal of basic and applied medical sciences. 2011;1(1):89-92.

16. Khare CP. Indian Medicinal Plants: An Illustrated Dictionary. New Delhi: Springer India (P) Ltd; 2007. p. 238-239.

17. Flayeh RAA. Antifungal activity of some plant extract and alum on yeast isolated from mouth lesions. Euphrates journal of agriculture science. 2010;2(2):1-4.

18. Rupesh S, Winnier JJ, Nayak UA, Rao AP, Reddy NV. Comparative evaluation of the effects of an alum- containing mouth rinse and a saturated saline rinse on the salivary levels of streptococcus mutans. Journal of Indian society of pedodontics and preventive dentistry. 2010;3(8):138-44.

19. Altaei TS, Jubouri RHA. Evaluation of the efficacy of alum suspension in treatment of recurrent ulcerative ulceration. J College Dentistry. 2005;17(2):45-8.

20. Nadkarni KM. Indian Plants and Drugs. New Delhi: Srishti Book Distributors; 2005. pp. 31, 151-152.

21. Faraji R, Rahimi MA, Assarehzadegan M. Prevalence of Vaginal Candidiasis infection in women referred to Kermanshah hygienic centres Iran in 2010. Life Science Journal. 2012;9(4):1280-3.

22. Qarshi MH. Jame ul Hikmat. New Delhi: Idarae Kitabul Shifa; 2011. pp. 1121-1123.

23. Monjaraz S, Peggy EA, Victor MV, Beatriz X, Yolandadel CP. A molecular epidemiological study of prevalence of Candida spp. in women in the city of Tuxtla Gutierrez, Chiapas. International biotechnology color journal. 2012;2(2):6-14.

24. Saeed S, Tariq P. Antimicrobial activities of Emblica officinalis and Coriandrum sativum against Gram Positive bacteria and Candida albicans. Pak J Bot. 2007;39(3):913-7.

25. Nafis I, Nafisi K. Urdu translation by Kabeeruddin. New Delhi: Ejaz Publication; 1934. p. 277-278.

Cite this article as: Manzoor M, Sadiq S, Shahzad N. Efficacy of Amla (Emblica officinanis) and Shibe yamani (potash alum) in the management of Candida vaginitis: a randomized standard controlled trial. Int J Reprod Contracept Obstet Gynecol 2016;5:1601-6. 